\section{Wulff Possart Wins Award in France}

D rofessor Wulff Possart, Director of the Chair of Adhesion and Interphases in Polymers at Saarland University, has been awarded the "Prix Dedale 2013" by the French Adhesion Society for his scientific work in the field of adhesion research. This internationally coveted award was presented on 6 December 2013 at the annual "Journées d'Etude sur l'Adhesion”. The renowned

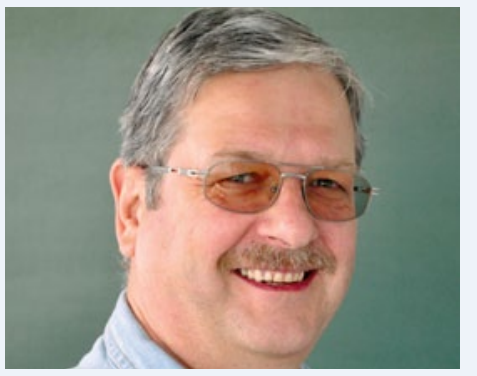

Prof. Wulff Possart was awarded the "Prix Dedale 2013" by the French Adhesion Society.

"Prix Dedale", which has been presented every two years since the foundation of the Society at the beginning of the 1990s, is not the first accolade that Possart has received for his outstanding achievements in the field of adhesion research. In 2012, he was the first German scientist to receive the highly renowned US-American "Award for Excellence in Adhesion Science”. In addition, Possart is a bearer of the Wake Memorial Medal, which was presented to him by the British Society for Adhesion and Adhesives in 2008.

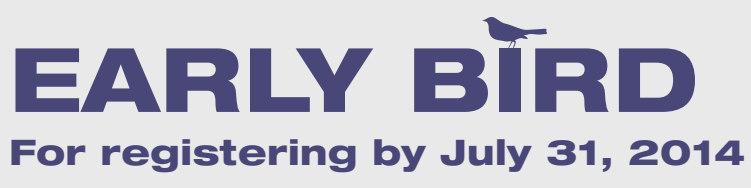

FINISHING SYMPOSIUM

\section{www.mkvs.de}

\title{
Global Plasticizer Consumption on the Increase
}

$\mathrm{n}$ order to render brittle materials soft,

flexible or ductile, millions of tonnes of plasticizers are processed every year. The market research institute Ceresana forecasts that the global market value of plasticizers will increase to more than US\$ 19.5 billion in 2020. It says that the major growth markets will be Asia-Pacific and Eastern Europe.

According to the report, the highest growth rates will continue to be in the BRIC countries (Brazil, Russia, India, China), but the USA is also likely to increase demand for plasticizers during the coming years after the losses incurred in the past. The analysts expect demand in Western Europe to hardly exceed stagnation. However, an increasing demand for phthalate-free plasticizers will stimulate the market.

\section{Growth market phthalate-free plasticizers}

Health concerns of consumers and possible further bans on the use of phthalates are leading to an increased demand for phthalate-free and biobased plasti- cizers. Phthalate plasticizers, especially DEHP, are expected to lose even higher market shares to phthalate-free products than they did in the past. Wherever new production capacities are created in Western Europe, these are almost exclusively dedicated to the production of phthalate-free plasticizers. Even China is in the meantime exhibiting excess capacities for DEHP. So far, DEHP accounted for about $60 \%$ of the Asian-Pacific market.

The study provides demand and revenue data for a total of 45 countries. Additionally, demand in the application fields of profiles, films, cables, floorings, other plastics, elastomers, paints/ varnishes and elastomers for the 18 most important sales markets are analysed in detail. The study also provides data on demand development and company profiles of the largest manufacturers of plasticizers.

For further information, please visit: www. ceresana.com/de/Marktstudien/Additive/ Weichmacher 